\title{
Differential diagnosis and treatment of acute cauda equina syndrome in the human immunodeficiency virus positive patient: a case report and review of the literature
}

George Panos ${ }^{1,2^{*}}$, Dionysios C. Watson ${ }^{2}$, loannis Karydis ${ }^{1}$, Dimitrios Velissaris ${ }^{3}$, Marina Andreou ${ }^{3}$, Vasilis Karamouzos ${ }^{3}$, Maria Sargianou $^{2}$, Antonios Masdrakis $^{1}$, Paraskevi $\mathrm{Chra}^{4}$ and Lavrentios Roussos ${ }^{5}$

\begin{abstract}
Background: Acute cauda equina syndrome is an uncommon but significant neurologic presentation due to a variety of underlying diseases. Anatomical compression of nerve roots, usually by a lumbar disk hernia is a common cause in the general population, while inflammatory, neoplastic, and ischemic causes have also been recognized. Among human immunodeficiency virus (HIV) infected patients with acquired immunodeficiency syndrome, infectious causes are encountered more frequently, the most prevalent of which are: cytomegalovirus, herpes simplex virus 1/2, varicella zoster virus, and Mycobacterium tuberculosis infections. Studies of cauda equina syndrome in well-controlled HIV infection are lacking. We describe such a case of cauda equina syndrome in a well-controlled HIV-infected patient, along with a brief review of the literature regarding the syndrome's diagnosis and treatment in individuals with HIV infection.

Case presentation: A 36-year-old Greek male, HIV-positive patient presented with perineal and left hemiscrotal numbness, lumbar pain, left-sided sciatica, and urinary incontinence. Magnetic resonance imaging of the patient's lumbar spine revealed intrathecal migration of a fragment from an intervertebral lumbar disk exerting pressure on the cauda equina. A cerebrospinal fluid examination, brain computed tomography scan, spine magnetic resonance imaging, and serological test results were negative for central nervous system infections. Our patient underwent emergency neurosurgical spinal decompression, which resolved most symptoms, except for mild urinary incontinence.

Conclusions: Noninfectious etiologies may also cause cauda equina syndrome in HIV-infected individuals, especially in well-controlled disease under antiretroviral therapy. Prompt recognition and treatment of the underlying cause is important to minimize residual symptoms. Targeted antimicrobial chemotherapy is used to treat infectious causes, while prompt surgical decompression is favored for anatomical causes of cauda equina syndrome in the HIV-infected patient.
\end{abstract}

Keywords: HIV, Cauda equina syndrome, Lumbar disk fragment, CMV, Myeloradiculopathy, Mycobacterium tuberculosis

\footnotetext{
*Correspondence: george.panos@upatras.gr; panmedix@otenet.gr

${ }^{1}$ Special Infections Unit, 2nd Internal Medicine Clinic, 1st I.K.A. Penteli General

Hospital, Melissia, Athens, Greece

${ }^{2}$ Department of Infectious Diseases, Patras University General Hospital, 26504

Rion, Patras, Greece

Full list of author information is available at the end of the article
} 


\section{Background}

Cauda equina syndrome (CES) is a polyradiculopathy resulting from nerve compression or inflammation of the lower spinal cord, which commonly presents with motor and sensory abnormalities of the lower limbs, along with bladder and sphincter dysfunction. Numerous causes of CES have been reported to date, including spinal disk herniation, trauma, spinal stenosis, iatrogenic causes, neoplasms, ischemia, inflammation, and infections [1]; an etiology for a portion of cases cannot be identified. In patients with advanced human immunodeficiency virus/acquired immunodeficiency syndrome (HIV/AIDS), central nervous system (CNS) infections, usually due to cytomegalovirus (CMV) or Mycobacterium tuberculosis (MTB), comprise the most common causes of CES [2-5]. However, noninfectious processes may also lead to CES in individuals infected with HIV, especially when the disease is well controlled, as in the case report that follows. Prompt diagnosis of the syndrome, identification of the underlying cause, and appropriate treatment are crucial, since progression is rapid and prognosis can sometimes be unfavorable if specific treatment is delayed, especially in the context of HIV infection.

\section{Case presentation}

A 36-year-old Greek male, HIV-positive patient was admitted to the Neurology Department due to perineal and left hemiscrotal numbness, lumbar pain, left-sided sciatica, and urinary incontinence; his symptoms began 5 days prior to admission, and were not accompanied by fever. The patient's occupational history was significant for frequent weight-lifting during his daily duties as an orderly. He had been on a triple antiretroviral regimen with didanosine (ddI), d4T (stavudine), and efavirenz for the past 6 years, while diagnosis of HIV was made 12 years earlier. Recent testing reported a $\mathrm{CD} 4^{+}$cell count of 1036 cells $/ \mathrm{mL}$ and an undetectable HIV viral load $(<50$ copies/mL); the Center for Diseases Control (CDC) stage of his disease was C3.

The neurological examination revealed decreased strength of the left gastrocnemius and absence of the left ankle jerk reflex, while his plantar reflexes were indifferent bilaterally. The remaining physical examination was noncontributory.

Given that the patient's neurological signs and symptoms were indicative of CES, a magnetic resonance imaging (MRI) scan of his lumbar spine was initially performed. Imaging revealed left dorsolateral intervertebral disc herniation of L3-L4, prominent dorsomedian intervertebral disc herniation of L5-S1, and a small fragment within the vertebral canal (at S1) that was exerting pressure on cauda equina fibers. The latter finding was compatible with a fragment originating from the L5-S1 intervertebral disk. A brain computed tomography (CT) scan, cerebrospinal fluid (CSF) examination, and serological test results for $\mathrm{CNS}$ infections, including $\mathrm{CMV}$ and herpes simplex virus $1 / 2(\mathrm{HSV}-1 / 2)$ were negative. Further testing for infectious causes would have been pursued in the absence of an obvious anatomical cause of the observed syndrome.

Because of the acute onset of CES in our patient, emergency neurosurgical spinal decompression was deemed necessary. The procedure was successful overall, leading to resolution of most neurological symptoms, with the exception of a persistent, mild urinary incontinence. Specifically, early postoperative neurological findings were largely limited to the left lower limb and perineum, and included: slightly decreased lower limb muscle strength (L5-S1 myotomes), mild sensory impairment on the lateral surface of his foot (L5 dermatome), and mild paresthesia of his buttocks, left hemiscrotum, and dorsolateral thigh. Two-point discrimination was $1.5-2 \mathrm{~cm}$, with a mild decrease on his left side. Vibration sensation in the affected regions was normal, and his plantar reflexes were flexor bilaterally.

Neurological follow-up performed 1 week later revealed physiological muscle strength, no sensory deficits, and partial recovery of his bladder dysfunction. Urological symptoms have been previously described in the literature as presenting a delayed recovery following decompression surgery [6]. Although intervertebral lumbar disc herniation with posterior migration of a sequestered disk fragment has been previously reported as a rare cause of CES in immunocompetent patients [7], this is the first case report in an HIV-positive patient.

\section{Discussion}

\section{Differential diagnosis}

Despite the relative rarity of CES among HIV-positive patients, prompt diagnosis and treatment of the syndrome is crucial due to the potential of persistent debilitating symptoms [8] (such as permanent loss of bowel/ bladder control and paralysis of the legs). It is, thus, necessary to perform an immediate and thorough clinical, imaging, and laboratory investigation in every HIVpositive patient whose symptoms are suggestive of the syndrome in order to identify its cause. An MRI scan of the lumbar spine should be performed within the first few hours of symptom onset [9]. This aims to quickly identify many of the causes of the syndrome (Table 1), such as simple protrusion of the intervertebral disc, compression of the cauda equina, or focal inflammation (for example, caused by infection) [8].

In the general population, CES usually results from compression of spinal nerve roots due to intervertebral disk hernias, vertebral canal stenosis, or spinal neoplasms [1]. Intervertebral lumbar disc herniation with 
Table 1 Causes of cauda equina syndrome in human immunodeficiency virus positive patients

\begin{tabular}{lll}
\hline Anatomical compression & $\begin{array}{l}\text { Spinal infection (especially } \\
\text { in advanced HIV/AIDS) }\end{array}$ & Other causes \\
\hline Abscess [32, 33] & Cryptococcus [34] & Connective tissue disease [24, 35] \\
Spinal hematoma (for example, from trauma) [36] & Cytomegalovirus [37] & latrogenic adhesive arachnoiditis [38] \\
Intervertebral disk hernia [28] & Epstein-Barr virus [39] & HIV (idiopathic cauda equina syndrome) [14] \\
Intrathecal disk fragment [7] & Herpes simplex virus (mainly HSV-2) [19] & Spinal ischemia [40] \\
Pathologic spinal fracture (for example, due to & Treponema pallidum [22] & \\
Osteoporosis or neoplasia) [41] & & \\
Spinal neoplasia (especially lymphoma) [42-44] & Schistosoma [45] & \\
Vertebral canal stenosis [46] & Toxoplasma [47] & \\
& Mycobacterium tuberculosis [20] & \\
& Varicella zoster virus [48, 49] &
\end{tabular}

HIV human immunodeficiency virus, AIDS acquired immunodeficiency syndrome

posterior migration of a disc fragment has been reported as a rare cause of the syndrome in otherwise healthy persons $[7,10,11]$. As for noncompressive causes, ischemia and spinal arachnoiditis have been described [1]. These processes could be the cause of CES in HIVinfected individuals, especially in the setting of wellcontrolled infection under antiretroviral therapy.

The differential diagnosis of CES in immunocompromised patients with HIV infection includes several more, mostly infectious, causes (Table 1). In HIV-infected individuals with advanced HIV/AIDS, the syndrome may present as an acute polyradiculopathy $[12,13]$. When this occurs, it is often caused by CNS infection that affects the cauda equina or conus medullaris. CMV and MTB are the most common infectious causes among HIV-positive patients [5, 13, 14], which can be in the context of concurrent infection of the retina and other organs $[2,13]$.

In order to rule out CMV CNS infection, a lumbar puncture may be performed for CSF analysis, along with serological and molecular testing. CSF laboratory findings suggestive of CMV CNS infection include high cell count with unaltered polymorphonuclear cells (usually $>60 \%)$, decreased glucose $(<50 \%$ of serum measurement), and significantly increased protein levels, whereas neoplastic cells are absent $[2,13]$. Nevertheless, reports of normal CSF findings in CMV infections have also been published [13]. Thus, polymerase chain reaction (PCR) of the CSF for CMV DNA is also required before CMV infection is excluded in HIV-positive patients (92\% sensitivity and $94 \%$ specificity) [15], whereas branched chain DNA (bDNA) assay for CMV DNA and immunoperoxidase staining for CMV antigen can also be considered [16, 17]; CSF viral cultures are less useful for initial diagnosis, as they lack sensitivity $[13,15]$. In addition to molecular testing, MRI with intravenous gadolinium contrast may be necessary to detect neural CMV lesions [18].
Myeloradiculitis is usually a complication of tuberculous meningitis or HSV-2 CNS infection that can also lead to CES (even in successfully treated patients) $[4,19]$ and yields negative CSF examination results [20, 21]. Depending on patient history and locally endemic diseases, ruling out HSV-1/2, varicella zoster virus (VZV), and Mycobacterium tuberculosis (MTB) should also be considered; molecular testing may also be necessary in these cases, as other testing can be nondiagnostic $[4,19]$; other, more rare causes should be considered on an individualized basis.

Also, impaired immune response in HIV-positive patients with syphilis can cause an atypical, aggressive form of neurosyphilis, which can manifest as painful polyradiculopathy [22]; rapidly progressive, asymmetrical sensorimotor abnormalities of the lower limbs, bladder and sphincter are the hallmark of this form of neurosyphilis. In the full-blown syndrome, the patient may present with sensory loss of the lower body's dorsal surface, bilateral sciatic nerve pain, paresthesia, decreased strength of the lower limbs or chronic flaccid paraplegia, absence of deep tendon reflexes, and bladder/sphincter dysfunction [1]. Lymphomas have also been reported to cause CES in HIV-positive patients [5, 23]. Finally, primary CES in these patients is a benign, idiopathic form of the syndrome that has a slow clinical progression, mild neurologic deficits, and a generally better prognosis, which may explain those cases where no anatomical causes, infectious agents or neoplastic cells can be identified [24]. CSF examination results in the primary syndrome reveal moderate mononuclear pleocytosis and mildly increased protein levels.

A systematic meta-analysis of more than 200 individual cases of CES found that the majority (84 \%) of patients experience a progressive development of symptoms, beginning with sensory-motor findings in the lower extremities (early CES) [25]. Bowel and sphincter symptoms tend to develop later on, in what the authors of the study describe as "incomplete CES" and "CES in retention" [25]. 
Thus, suspecting CES when bilateral lower limb and/or perineal sensorimotor findings are present could lead to more rapid diagnosis and subsequent management in both well-controlled and advanced HIV infection.

\section{Treatment}

Treatment should always be specific, unless the cause of the syndrome cannot be identified. In the case of the latter, short-term alleviation of symptoms and long-term complete neurological recovery of the patient are sought.

In the case of lumbar disk herniation causing CES in HIV-positive patients, surgery is considered more effective than medical management in the short term [26]. In the single relevant study, no significant difference in the response of HIV-infected individuals to surgical treatment of lumbar disk herniation was found, as compared to uninfected patients [27]. It is estimated that $1-3 \%$ of all patients with intervertebral lumbar disc herniation may manifest with CES [28, 29]. These cases of the syndrome, as well as those caused by other anatomical compressive phenomena, undergo surgical decompression that is performed within the first 24 hours of symptom presentation, in order to achieve maximum postoperative neurological recovery [29, 30]. Delayed surgical decompression (more than 48 hours after symptom onset versus treatment within 24-48 hours) has been correlated with a much higher rate of postoperative bladder and anal sphincter dysfunction, serious motor deficits, sexual dysfunction, and persistent pain [29].

In HIV-positive patients, when CES is due to CMV CNS infection, treatment may consist of intravenous administration of ganciclovir for 2-3 weeks; foscarnet can also be added to the treatment regimen when there is an increased risk for treatment failure, as in patients who have previously received ganciclovir, or in those with persistent polymorphonuclear pleocytosis, decreased glucose, and/or detection of CMV in serial CSF tests $[3,31]$. In ganciclovir-resistant cases, foscarnet infusion can be performed alone or in combination with cidofovir. Progression of neurological symptoms is usually controlled within 2 weeks of treatment, while serious defects may persist even after treatment completion $[2,12]$. Contrarily, in idiopathic CES spontaneous resolution of the syndrome is most often the case [12].

Initiation of empirical treatment may be considered in advanced HIV/AIDS patients with CES until the etiology is revealed, in order to prevent irreversible progression of neurological deficits [4]. Given the high occurrence of Herpesviridae and MTB infections leading to CES among HIV-infected patients, it may be reasonable to consider ganciclovir, acyclovir, and antimycobacterials in empirical regimens, while patient history and findings will further guide the empirical treatment selection [4].

\section{Conclusions}

It is important for acutely presenting CES to be suspected in patients with bilateral lower limb and/or perineal sensorimotor deficits, so as to mitigate permanent neurological damage. In working up HIV-positive patients, it can be important to exclude infectious causes of the syndrome, but differential diagnosis should also include etiologies leading to CES in the general population, especially in patients with well-controlled HIV infection.

\section{Authors' contributions}

GP diagnosed and treated the patient, wrote and revised the manuscript. DCW wrote the manuscript and searched the literature. DV, VK, IK, and PC wrote the manuscript. MA and MS searched the literature. AM treated the patient and searched the literature. LR treated the patient and revised the manuscript. All authors read and approved the final manuscript.

\section{Competing interests}

The authors declare that they have no competing interests.

\section{Consent}

Written informed consent was obtained from the patient for publication of this case report and any accompanying images. A copy of the written consent is available for review by the Editor-in-Chief of this journal.

\section{Author details}

${ }^{1}$ Special Infections Unit, 2nd Internal Medicine Clinic, 1st I.K.A. Penteli General Hospital, Melissia, Athens, Greece. ${ }^{2}$ Department of Infectious Diseases, Patras University General Hospital, 26504 Rion, Patras, Greece. ${ }^{3}$ Internal Medicine Department, University Hospital of Patras, 26504 Rion, Patras, Greece. ${ }^{4}$ Department of Microbiology, Benakio-Korgialenio Hospital, 1 Erythrou Staurou Street, 11526 Athens, Greece. ${ }^{5}$ Neurosurgery Clinic, K.A.T. Hospital, 2 Nikis Street, 14561 Kifissia, Athens, Greece.

Received: 30 April 2015 Accepted: 17 April 2016

Published online: 06 June 2016

\section{References}

1. Orendacova J, Cizcova D, Kafka J, Lukacova N, Marsala M, Sulla I, et al. Cauda equina syndrome. Prog Neurobiol. 2001;64(6):613-37.

2. Jacomet C, Lebrette M, el Amrani M, Monfort L, Gozlan J, Girard P, et al. Lesions of the conus medullaris and the cauda equina caused by cytomegalovirus in HIV infection. 7 cases. Presse Med. 1995;24(11):527-30.

3. Cohen B, McArthur J, Grohman S, Patterson B, Glass J. Neurologic prognosis of cytomegalovirus polyradiculopathy in AIDS. Neurology. 1993:43(3 Pt 1):493-9.

4. Corral I, Quereda C, Casado J, Cobo J, Navas E, Perez-Elias M, et al. Acute polyradiculopathies in HIV-infected patients. J Neurol. 1997;244(8):499-504.

5. Candy S, Chang G, Andronikou S. Acute myelopathy or cauda equina syndrome in HIV-positive adults in a tuberculosis endemic setting: MRI, clinical, and pathologic findings. AJNR Am J Neuroradiol. 2014;35(8):1634-41.

6. Hussain S, Gullan R, Chitnavis B. Cauda equina syndrome: outcome and implications for management. Br J Neurosurg. 2003;17(2):164-7.

7. Tatli M, Guzel A, Ceviz A, Karadag O. Posterior epidural migration of sequestered lumbar disc fragment causing cauda equina syndrome. Br J Neurosurg. 2005;19(3):257-9.

8. Ma B, Wu H, Jia LS, Yuan W, Shi GD, Shi JG. Cauda equina syndrome: a review of clinical progress. Chin Med J. 2009;122(10):1214-22.

9. Saint-Louis LA. Lumbar spinal stenosis assessment with computed tomography, magnetic resonance imaging, and myelography. Clin Orthop Relat Res. 2001;384:122-36.

10. Dosoglu M, Is M, Gezen F, Ziyal M. Posterior epidural migration of a lumbar disc fragment causing cauda equina syndrome: case report and review of the relevant literature. Eur Spine J. 2001;10(4):348-51. 
11. Bonaroti $E$, Welch W. Posterior epidural migration of an extruded lumbar disc fragment causing cauda equina syndrome. Clinical and magnetic resonance imaging evaluation. Spine. 1998;23(3):378-81.

12. So Y, Olney R. Acute lumbosacral polyradiculopathy in acquired immunodeficiency syndrome: experience in 23 patients. Ann Neurol. 1994 35(1):53-8.

13. Miller R, Fox J, Thomas P, Waite J, Sharvell Y, Gazzard B, et al. Acute lumbosacral polyradiculopathy due to cytomegalovirus in advanced HIV disease: CSF findings in 17 patients. J Neurosurg Psychiatry. 1996:67(5):456-60.

14. Robinson-Papp J, Simpson DM. Neuromuscular diseases associated with HIV-1 infection. Muscle Nerve. 2009;40(6):1043-53.

15. Singh N, Thomas F. Progressive polyradiculopathy in HIV. Medscape Reference; 2011. http://emedicine.medscape.com/article/1168009. Accessed 25 Mar 2012

16. Marmaduke D, Brandt J, Theil K. Rapid prognosis of cytomegalovirus in the cerebrospinal fluid of a patient with AIDS-associated polyradiculopathy. Arch Pathol Lab Med. 1991;115(11):1154-7.

17. Flood J, Drew W, Miner R, Jekic-McMullen D, Shen L, Kolberg J, et al. Diagnosis of CMV polyradiculopathy and documentation of in vivo anti-CMV activity in cerebrospinal fluid by using branched DNA signal amplification and antigen assays. J Infect Dis. 1997;176(2):348-52.

18. Kameda K, Shirano M, Hadano Y, Kasamatsu Y, Nakamura T, Ota M, et al. Cytomegalovirus polyradiculopathy in three Japanese patients with AIDS. Intern Med. 2015;54(5):513-8.

19. Miguelez M, Correa-Nazco V, Linares M, Laynez P, Gonzales M, Martinez A. Lumbosacral polyradiculomyelitis caused by HSV in a patient with AIDS. An Med Interna. 1999;16(8):417-9.

20. Hernandez-Albujar S, Arribas J, Royo A, Gonzalez-Garcia J, Pena J, Vazquez J. Tuberculous radiculomyelitis complicating tuberculous meningitis: case report and review. Clin Infect Dis. 2000;30(6):915-21.

21. Corral I, Quereda C, Navas E, Perez-Elias M, Jover F, Moreno S. Sacral myeloradiculitis complicating genital herpes in a HIV- infected patient. Int J STD AIDS. 2005;16(2):175-8.

22. Lanska M, Lanska D, Schmidley J. Syphilitic polyradiculopathy in an HIVpositive man. Neurology. 1988;38(8):1297-301.

23. Leger J, Henin D, Belec L, Mercier B, Cohen L, Bouche P, et al. Lymphoma induced polyradiculopathy in AIDS: two cases. J Neurol. 1992;239(3):132-4.

24. Ahn NU, Ahn UM, Nallamshetty L, Springer BD, Buchowski JM, Funches L, et al. Cauda equina syndrome in ankylosing spondylitis (the CES-AS syndrome): meta-analysis of outcomes after medical and surgical treatments. J Spinal Disord. 2001;14(5):427-33.

25. Sun JC, Xu T, Chen KF, Qian W, Liu K, Shi JG, et al. Assessment of cauda equina syndrome progression pattern to improve diagnosis. Spine (Phila $\mathrm{Pa}$ 1976). 2014;39(7):596-602.

26. Bruggeman AJ, Decker RC. Surgical treatment and outcomes of lumbar radiculopathy. Phys Med Rehabil Clin N Am. 2011;22(1):161-77.

27. Eyenga VC, Ngowe NN, Minkande JZ, Ngah JE. Kinetics of regression of sciatica and pain in the low back after lumbar macrodiscectomy in human immunodeficiency virus carriers. Spine (Phila Pa 1976). 2008;33(13):E411-13.

28. Ghang $H$, Nakagawa H, Mizuno J. Lumbar herniated disc presenting with cauda equina syndrome. Long-term follow-up of four cases. Surg Neurol. 2000;53(2):100-4.

29. Shapiro S. Medical realities of cauda equina syndrome secondary to lumbar disc herniation. Spine. 2000;25(3):248-51.

30. Radulovic D, Tasic G, Jocovic M, Nicolic I. The role of surgical decompression of cauda equina syndrome in lumbar disc herniation and recovery of bladder dysfunction. Med Pregl. 2004;57(7-8):327-30.

31. Anders H, Weiss N, Bogner J, Goebel F. Ganciclovir and foscarnet efficacy in AIDS-related CMV polyradiculopathy. J Infect. 1998;36(1):29-33.

32. Reihsaus E, Waldbaur H, Seeling W. Spinal epidural abscess: a meta-analysis of 915 patients. Neurosurg Rev. 2000;23(4):175-204. discussion 205.

33. Cohen DB. Infectious origins of cauda equina syndrome. Neurosurg Focus. 2004;16(6):e2.

34. Jongwutiwes U, Malathum K, Sungkanuparph S. Cryptococcal meningoradiculitis: an atypical presentation after initiation of antiretroviral therapy. J Med Assoc Thail. 2007;90 Suppl 2:85-8.

35. Kawaji $\mathrm{H}$, Miyamoto $M$, Gembun $Y$, Ito $H$. A case report of rapidly progressing cauda equina symptoms due to rheumatoid arthritis. J Nippon Med Sch. 2005;72(5):290-4.
36. Chen HJ, Liang CL, Lu K, Liliang PC, Tsai YD. Cauda equina syndrome caused by delayed traumatic spinal subdural haematoma. Injury. 2001;32(6):505-7.

37. Lasso M, Perez J, Noriega L, Albert F, Gonzalez P, Malebran A. Polyradiculopathy caused by cytomegalovirus in AIDS patients: successful treatment with highly active antiretroviral therapy (HAART). Rev Med Chil. 2001;129(9):1061-4.

38. Killeen T, Kamat A, Walsh D, Parker A, Aliashkevich A. Severe adhesive arachnoiditis resulting in progressive paraplegia following obstetric spinal anaesthesia: a case report and review. Anaesthesia. 2012;67(12):1386-94.

39. Majid A, Galetta SL, Sweeney CJ, Robinson C, Mahalingam R, Smith J, et al. Epstein-Barr virus myeloradiculitis and encephalomyeloradiculitis. Brain. 2002;125(Pt 1):159-65

40. Wong SS, Roche-Nagle G, Oreopoulos G. Acute thrombosis of an abdominal aortic aneurysm presenting as cauda equina syndrome. J Vasc Surg. 2013; 57(1):218-20.

41. Muthukumar T, Butt SH, Cassar-Pullicino VN, McCall IW. Cauda equina syndrome presentation of sacral insufficiency fractures. Skelet Radiol. 2007; 36(4):309-13.

42. Giobbia M, Carniato A, Scotton PG, Vaglia A, Marchiori GC. Primary EBVassociated cauda equina lymphoma. J Neurol. 1999;246(8):739-40.

43. Knopp EA, Chynn KY, Hughes J. Primary lymphoma of the cauda equina: myelographic, CT myelographic, and MR appearance. AJNR Am J Neuroradiol. 1994;15(6):1187-9.

44. Kagaya H, Abe E, Sato K, Shimada Y, Kimura A. Giant cauda equina schwannoma. A case report. Spine (Phila Pa 1976). 2000;25(2):268-72.

45. Lobo PP, Coelho M, Geraldes R, Santos C, Gracio M, Rosa MM, Antunes JL. Myeloradiculopathy associated to Schistosoma mansoni. BMJ Case Reports. 2011;2011

46. Johnsson KE, Sass M. Cauda equina syndrome in lumbar spinal stenosis: case report and incidence in Jutland, Denmark. J Spinal Disord Tech. 2004; 17(4):334-5.

47. De Bonis P, Cingolani A, Pompucci A, Tartaglione T, Larocca LM, Teofili L. Cauda equina enhancing lesion in an HIV-infected patient. Case report and literature review. Mediterr J Hematol Infect Dis. 2011;3(1):e2011042.

48. Buonsenso D, Focarelli B, Valentini P, Onesimo R. IVIG treatment for VZVrelated acute inflammatory polyneuropathy in a child. BMJ Case Reports. 2012;2012

49. Chretien F, Gray F, Lescs MC, Geny C, Dubreuil-Lemaire ML, Ricolfi F, et al. Acute varicella-zoster virus ventriculitis and meningo-myelo-radiculitis in acquired immunodeficiency syndrome. Acta Neuropathol. 1993;86(6):659-65.

\section{Submit your next manuscript to BioMed Central and we will help you at every step:}

- We accept pre-submission inquiries

- Our selector tool helps you to find the most relevant journal

- We provide round the clock customer support

- Convenient online submission

- Thorough peer review

- Inclusion in PubMed and all major indexing services

- Maximum visibility for your research

Submit your manuscript at www.biomedcentral.com/submit 